\title{
THE ACCEPTANCE OF MOBILE PAYMENT AND SUSTAINABLE USAGE INTENTION IN MALAYSIA: AN ANALYSIS BASED ON UNIFIED THEORY OF ACCEPTANCE AND USE OF TECHNOLOGY (UTAUT)
}

\author{
Cao Yong ${ }^{\mathrm{i}}$ \\ Jacquline Tham, \\ S. M. Ferdous Azam, \\ Ali Khatibi \\ Postgraduate Centre, \\ Management and Science University (MSU), \\ section 13, 40100 Shah Alam, Selangor, \\ Malaysia
}

\begin{abstract}
:
Mobile payment refers to a payment method by which a consumer pays a bill for goods or services through a mobile terminal. mobile payment users can send payment instructions directly or indirectly to a bank financial enterprise via mobile devices or proximity sensing devices, thereby enabling currency payments and funds transfers. It realizes the integration of terminal equipment, Internet, application providers and financial institutions, and completes financial business such as currency payment. However, the adoption rates of this payment method are relatively low in Malaysia. This research aims to identify and explore key factors that affect the decision of whether to use mobile payments. Qualitative and quantitative research are the main methodology in this research. The well-established theories, Unified Theory of Acceptance and Use of Technology (UTAUT) is applied to investigate user acceptance of mobile payments. An empirical model for acceptance of mobile payment in Malaysia is established in this paper. Survey data from mobile payments users are used to test the proposed hypothesis and the model. The result of data analysis shows that Malaysian consumers' perceptions of cost has no statistically significant relationship with attitude to adopt mobile payment. On the other hand, the factors of Effort Expectancy, Performance Expectancy, Social Influence and Consumer Trust play significant roles. The results of this study also have some practical implications for the spread and management of mobile payment industry in Malaysia and some suggestions are offered to mobile payment platform. At the end of this paper, the limitations and future research directions are listed.
\end{abstract}

'Correspondence: email runnersoft@qq.com 
JEL: M10; M15; D12

Keywords: Malaysia, acceptance, mobile payment, UTAUT, effort expectancy, performance expectancy, social influence, consumer trust, perceived cost

\section{Introduction}

The payment method used by consumers will have a significant impact on the future of a country's financial system and business model. Mobile payment system is becoming more and more popular in the financial field. It has great potential to replace cash and become the most popular means to complete transactions in the near future (OECD, 2012; Cocosila \& Trabelsi, 2016). The Malaysian government has also issued some policies to actively encourage Malaysians to move towards a cashless society. Bank Negara Malaysia (BNM) has launched a blueprint for the financial sector (2011-2020) to develop and manage the future of Malaysia's financial markets and payment systems (Ooi Widjaja, 2016).

However, the development of mobile payment is still in the infant stage in Malaysia, its uptake remains limited (Qasim \& Abu-Shanab, 2016). Statistic shows that the number of mobile payment users in Malaysia is only 3.2 million, and penetration is only $9.9 \%$ (Statista-MCMC, 2018).

Though there are many advantages of mobile shopping and payment, the usage in Malaysia is still very low, and the attitude to the channel of mobile shopping remains unclear (Ghazali, 2018). Due to the rapid rise of communication technologies, mobile payment system has emerged as a popular method to facilitate payment transactions. Notwithstanding its widespread use, what affects intention of mobile users towards paying through mobile phones and why in the context of developing market remain largely unanswered (Ting et al., 2016). Thus, the purpose of this paper is to study the factors of acceptance of mobile payment in Malaysia. This paper builds a model that affects the college students' acceptance of mobile payment in Malaysia, and makes a forecast on the long-term development of mobile payment in Malaysia and puts forward some useful suggestions.

\section{Literature Review}

This paper's theoretical constructs are based on Unified Theory of Acceptance and Use of Technology (UTAUT). This well-established theory is one of the most influential theories in clarifying and predicting users' acceptance and adoption in a new system and can be helpful to build a rigid theoretical foundation for this research.

UTAUT integrates eight adoption theory such as TRA, TAM, IDT, TPB, SCT, MM, C-TAM-TPB and model of PC Utilization and proposes the critical elements with regards to new information technology acceptance. UTAUT suppose that the four independent variables are direct determinant of usage intention and behavior. These four independent 
variables in UTAUT are Performance Expectancy (PE), Effort Expectancy (EE), Social Influence (SI), Facilitating Condition (FC). Furthermore, Gender, age, experience, and voluntariness of use are posited to mediate the impact of the four key constructs on usage intention and behavior (Venkatesh, 2003).

According to Venkatesh, Performance Expectancy (PE) is defined as the degree to which an individual believes that using the new technology will help him or her attain gains in job performance. This variable is similar to PU in TAM. Effort Expectancy (EE) is defined as the degree of ease associated with the use of a new technology. It refers to the perceived amount of effort that the user needs to put to learn and operate a new technology and it is similar to PEOU in TAM. Social Influence (SI) refers to the extent to which the individual is affected by the surrounding groups, which includes subjective norms (SN), social factors (SF) and public images (Image). Facilitating Conditions (FC) refers to the extent to which the individual feels the support of the organization on the related technology and equipment.

UTAUT also pointed out that there were four significant control variables affecting the independent variable above mentioned, namely, sex, age, experience and voluntariness. The results of Venkatesh (2003) study found that the compound effect of more than two control variables would make the effect more significant.

\section{Research Model and Hypotheses}

Based on these theories, the hypotheses are developed and then the research model is proposed. The independent variables are Performance Expectancy (PE), Effort Expectancy (EE), Social Influence (SI), Consumer Trust (CT) and Perceived Cost (PC), and Acceptance of mobile payment is the mediating variable and Sustainable Usage Intention (SUI) is the dependent variable.

\subsection{Performance Expectancy (PE)}

Performance Expectation refers to the extent to which individuals believe that the use of a new technology can help them improve their performance. With mobile applications, users can create faster processes on any work related to finance, and it is relatively safe to use mobile payment applications. As mobile payment can save a lot of time, it has a highly positive effect on the performance of the users. With the convenience provided by this application, many activities can be completed in a short time. The use of mobile banking. Furthermore, Mobile payments assist many people to gain profits, including making it easier to carry out financial transaction activities so that many people adopt the system in their daily activities (Oliveira et al., 2016). From the results above, the following hypothesis was drawn:

H1: Performance Expectancy of mobile payment services has a positive effect upon consumers' acceptance of mobile payment services in Malaysia. 


\subsection{Effort Expectancy (EE)}

Effort Expectancy was as the level of easiness related while using any system. In other words, it refers to the degree to which new technologies provide ease of use, which can reduce users' efforts in their work. Generally, if a payment system is conducted easily, many people are willing to use it. To some extent, mobile payment has such characteristics. mobile payment applications have a very positive impact on job expectations due to their ease of use. Mobile payment applications are also classified as user-friendly, so it may encourage many people to use it because of their ease of use and accuracy. It is because mobile payment uses a system easily understood by many people that it has a positive impact on business expectations (Slade, 2015). This leads to the following hypothesis.

H2: Effort Expectancy of mobile payment services has a positive effect upon consumers' acceptance of mobile payment services in Malaysia.

\subsection{Social Influence (SI)}

Social Influence is defined as the extent to which individuals think that people around them, such as colleagues' family and friends, have an impact on their use of a new technology. It relates to a person's beliefs about whether peers and people of importance to the person think he or she should engage in the behavior. Some scholars point out that adoption of a new technology is significantly affected by social institutional pressure (Bass, 1969). A technology may provide a positive impact when utilizing social networks because they will have more intentions (Musa, 2015). This study defines SI as a measure of the influence of important peers and other social groups, including friends, parents and colleagues, on acceptance of mobile payment in Malaysia. As Malaysia is a country with strong social labor division and cooperation, consumers tend to seek opinions from their families and friends on mobile payment experience, and their social influence may have a significant impact on consumers' willingness to use mobile payment. Therefore, the hypothesis for this study with regard to SI is proposed as:

H3: Social Influence has a positive effect upon consumers' acceptance of mobile payment services in Malaysia.

\subsection{Consumer Trust (CT)}

In literatures, trust is defined as the "extent to which an individual believes that using mobile commerce is secure and has no privacy threats" (Zhang et al., 2012). Trust is "highly conducive to such psychological forces as expectations, attitudes, willingness and perceived probability" (Kim et al., 2009). Trust is seen as an expression of security when making an exchange, or in another type of relationship (Garbarino \& Johnson, 1999). Empirically, researches showed that consumer trust and perceived risk have a greater impact on network services. In the context of mobile payment services, some scholars proposed that consumer trust must be for both the mobile service provider and the mobile technology 
(Chandra et al., 2010; Zhou, 2013). Therefore, the hypothesis for this study with regard to Consumer Trust is proposed as:

H4: Consumer Trust has a positive effect upon consumers' acceptance of mobile payment services in Malaysia.

\subsection{Perceived Cost (PC)}

Perceived Cost (PC) refers to the sum of the expenditures felt by the customer during the actual consumption process. It is the time, money, physical strength and energy involved in the customer's entire process of consuming the product or service. In Compass Acceptance Model for the analysis and evaluation of mobile service, Perceived Cost (PC) was thought to be a factor affecting the attitude toward mobile service (Amberg et al., 2004). Many empirical researches have discussed how perceived cost affect acceptance of network products (Soane et al., 2010; Benazić et al., 2015). Several studies suggest that Perceived Cost could be a major barrier to the adoption of new technologies in mobile phone services in Taiwan, Malaysia, Thailand and so on (Cheong \& Park, 2005, Wei et al., 2009; Phonthanukitithaworn, 2016). Therefore, the hypothesis for this study with regard to $\mathrm{PC}$ is proposed as:

H5: Perceived cost of mobile payment services has a negative effect upon consumers' acceptance of mobile payment services in Malaysia.

Figure 1: The conceptual framework

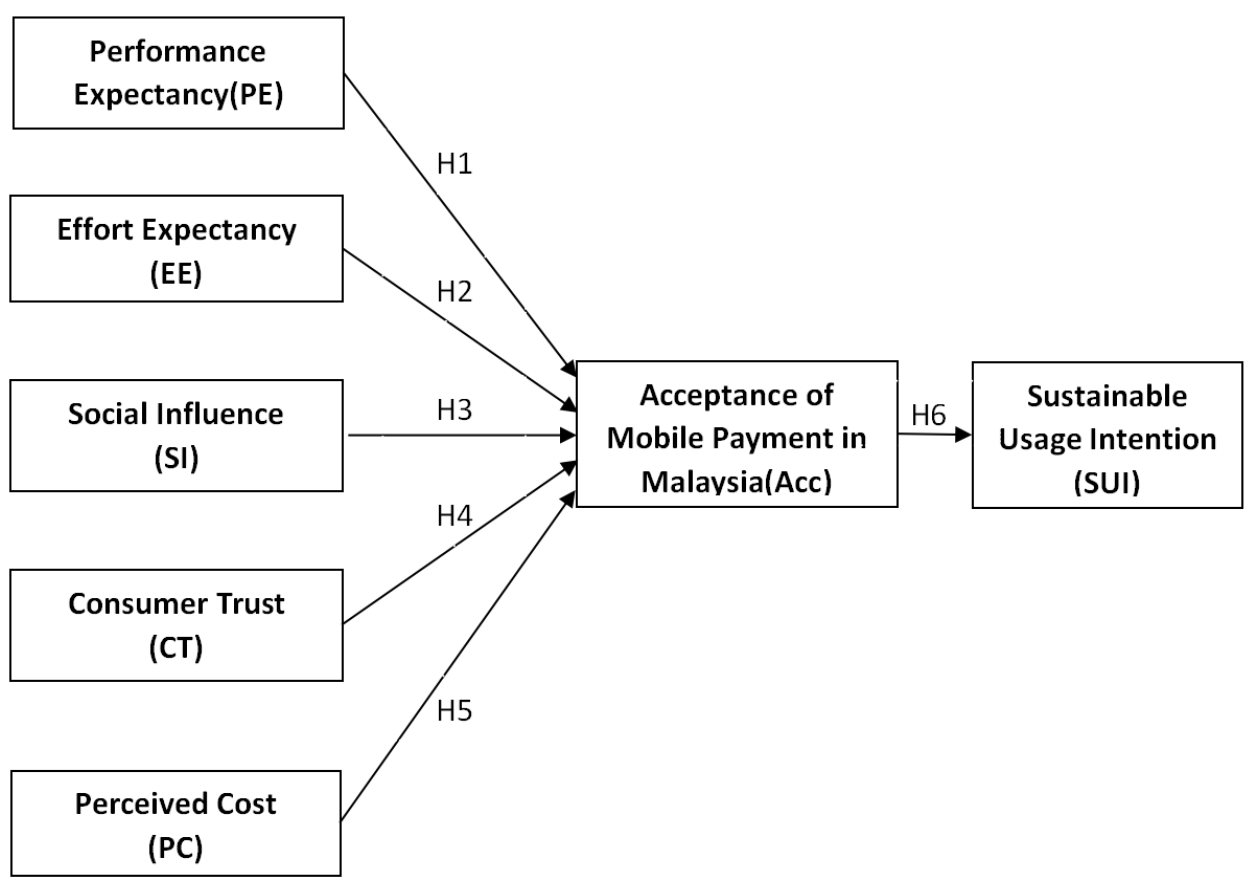

Source: Developed for this research 


\section{Research Methodology}

Survey has been selected as the central research methodology in this research. The multiitem scales measure was applied to this research in order to test the proposed research model. The statements are written for each item, and the participants were required to indicate whether they agreed or disagreed with the statements on a Likert scale. Some of the items in the survey were taken from previously published scales with appropriate psychometric properties research. The items were adopted or adapted to fit the context of mobile payments. After an extensive literature review on the topic, new items were also developed by this research.

Mobile payment users are the target participants for this survey, which does not necessarily suggest that the participants have adopted the services. Basically, this research will select the people in the economically developed Klang Valley, Kuala Lumpur area as the research object. Respondents were invited to participate in the survey by answering papery questionnaire.

The questionnaire collects two major types of information. One-part concerns participants' demographic information, and the other part is about participants' perceptions of each of the constructs in the proposed model. The demographic information includes gender, age, level of education, and occupation. The rest of the questionnaire asks for participants' the opinions of each item.

The sample size depends on several important criteria including statistical, managerial issues and budget. Statistics show that the number of mobile payment user in Malaysia is about 3.2 million. According to Sekaran \& Bouge (2010), it is adequate for this study with the sample size 384. A total of about 500 questionnaires were distributed to mobile payment users in Klang Valley, Malaysia and 390 valid were collected.

\section{Data Analysis}

The pilot study is a preliminary small-scale study conducted by researchers before a large-scale questionnaire is distributed, which can help them decide how to best conduct whole research projects. Table 1 outlined the result of the pilot study performed before the actual data collection. The purpose is to evaluate the reliability. Forty questionnaires were distributed in KL, and 31 were used for analysis.

Table 1: Result of Cronbach's Alpha for Pilot Study

\begin{tabular}{|l|c|}
\hline Variable & Cronbach's Alpha \\
\hline PE & 0.845 \\
\hline EE & 0.747 \\
\hline SI & 0.875 \\
\hline CT & 0.921 \\
\hline PC & 0.961 \\
\hline ACC & 0.942 \\
\hline SUI & 0.875 \\
\hline
\end{tabular}


Before large-scale distribution of questionnaires, pre-testing of the questionnaires is required. The purpose is to obtain high-quality questionnaires with high reliability. If there are items that do not meet the requirements, they need to be modified or deleted.

As can be seen from the above table, the Cronbach's Alpha values of all variables are greater than 0.7 , and the variable reliability in the pre-test questionnaire is verified to meet the requirements, and subsequent data analysis can be performed. The study questionnaire does not need to be modified.

Following the response from survey, the proposed hypotheses will be tested. SEM based analysis techniques will be used to analysis the data. First, the Confirmatory Factor Analysis (CFA) will be employed to assess the validity of the measurement for the model, then the proposed model will be tested using the Structural Equation Modeling (SEM), so that the causal structure of the model can be evaluated. The research will use AMOS to analyse the measurement model and the structural model.

The proposed research model was evaluated using structural equation modelling and employed a two-step modelling approach, including the assessment of the measurement model and the assessment of the structural model (Byrne, 2010). The assessment of the measurement model ensures that observed variables are appropriately loaded with regards to the factors they belonged to, with no significant cross-loading to an item of another factor. The assessment of the structural model determines the relationship between independent and dependent variables.

\subsection{Assessment of Measurement Model}

A confirmatory factor analysis using AMOS (v20) was conducted on all the items simultaneously to evaluate the validity of the items and the underlying constructs in the measurement model. The overall fit of the hypothesised model was assessed using eight common model-fit measures: goodness-of-fit (GFI), standardised root mean-square residual (SRMR), root mean-square error of approximation (RMSEA), comparative fit index (CFI), Tucker Lewis index (TLI), normalised fit index (NFI), adjusted goodness-offit (AGFI), and normed $\chi 2$ /df.

Table 2 summarizes the results for the model-fit indices, which show that the measurement model exhibits a good fit with the data collected. And the evaluation of the psychometric properties of the measurement model in terms of reliability and construct validity can be processed.

Table 2: Results of the measurement model across model-fit indices

\begin{tabular}{|l|c|c|c|}
\hline Fitness Indexes & Critical Values & Initial Indicators & Fitting Judgment \\
\hline $\mathrm{X} 2$ & & 945.264 & \\
\hline $\mathrm{df}$ & & 652 & $\mathrm{Y}$ \\
\hline $\mathrm{X} 2 / \mathrm{df}$ & $1-3$ & 1.450 & $\mathrm{Y}$ \\
\hline SRMR & $<0.05$ & 0.032 & $\mathrm{Y}$ \\
\hline GFI & $>0.9$ & 0.971 & Close to 0.9 \\
\hline AGFI & $>0.9$ & 0.865 & $\mathrm{Y}$ \\
\hline NFI & $>0.9$ & 0.913 & $\mathrm{Y}$ \\
\hline IFI & $>0.9$ & 0.970 & \\
\hline
\end{tabular}




\begin{tabular}{|l|c|c|c|}
\hline \hline TLI & $>0.9$ & 0.967 & Y \\
\hline CFI & $>0.9$ & 0.972 & Y \\
\hline RMSEA & $<0.08$ & 0.034 & Y \\
\hline
\end{tabular}

Construct validity was examined through the test for convergent and discriminant validity. Convergent validity was evaluated using the attributes of factor loading, average variance extracted (AVE), and construct reliability (CR). The values are provided in Table 3. It shows that all the scale items are highly loaded with respect to their constructs as all factor loadings are above the threshold value of 0.50 , and item reliability of each indicator, including CR, had scores above 0.70 , suggesting good reliability as well as good convergent validity. Notably, the CR values of the five constructs in the model are all above 0.85 which provides evidence that these measures consistently represent the same latent construct.

Table 3: Factor loadings, AVE, item reliability, and construct reliability of the five-factor CFA model

\begin{tabular}{|c|c|c|c|c|c|}
\hline Construct & Item & Factor Loading & SMC & $\mathrm{CR}$ & AVE \\
\hline \multirow{5}{*}{ PE } & PE1 & 0.869 & 0.755 & \multirow{5}{*}{0.860} & \multirow{5}{*}{0.562} \\
\hline & PE2 & 0.901 & 0.812 & & \\
\hline & PE3 & 0.780 & 0.608 & & \\
\hline & PE4 & 0.557 & 0.310 & & \\
\hline & PE5 & 0.568 & 0.323 & & \\
\hline \multirow{5}{*}{$\mathrm{EE}$} & EE1 & 0.754 & 0.569 & \multirow{5}{*}{0.860} & \multirow{5}{*}{0.551} \\
\hline & EE2 & 0.726 & 0.527 & & \\
\hline & EE3 & 0.707 & 0.500 & & \\
\hline & EE4 & 0.756 & 0.572 & & \\
\hline & EE5 & 0.767 & 0.588 & & \\
\hline \multirow{6}{*}{ SI } & SI1 & 0.763 & 0.582 & \multirow{6}{*}{0.862} & \multirow{6}{*}{0.512} \\
\hline & SI2 & 0.718 & 0.516 & & \\
\hline & SI3 & 0.617 & 0.381 & & \\
\hline & SI4 & 0.782 & 0.612 & & \\
\hline & SI5 & 0.769 & 0.591 & & \\
\hline & SI6 & 0.625 & 0.391 & & \\
\hline \multirow{7}{*}{ CT } & CT1 & 0.796 & 0.634 & \multirow{7}{*}{0.910} & \multirow{7}{*}{0.594} \\
\hline & $\mathrm{CT} 2$ & 0.823 & 0.677 & & \\
\hline & CT3 & 0.608 & 0.370 & & \\
\hline & CT4 & 0.836 & 0.699 & & \\
\hline & CT5 & 0.756 & 0.572 & & \\
\hline & CT6 & 0.740 & 0.548 & & \\
\hline & CT7 & 0.810 & 0.656 & & \\
\hline \multirow{5}{*}{ PC } & PC1 & 0.886 & 0.785 & \multirow{5}{*}{0.942} & \multirow{5}{*}{0.767} \\
\hline & PC2 & 0.870 & 0.757 & & \\
\hline & PC3 & 0.771 & 0.594 & & \\
\hline & PC4 & 0.920 & 0.846 & & \\
\hline & PC5 & 0.922 & 0.850 & & \\
\hline
\end{tabular}


The square root of AVE values was compared with the correlation estimates for assessing discriminant validity. The correlation matrix in Table 4 shows that the square root of AVE values is all larger than the correlation estimates, confirming that a satisfactory level of discriminant validity has been achieved. This evidence indicates that the measured variables have more in common with the construct they are associated with rather than other constructs in the model. Further, it indicates that all the constructs in the measurement model are significantly different from each other.

Table 4: Factor loadings comparison of correlation

estimates for the examination of discriminant validity

\begin{tabular}{|l|c|c|c|c|c|c|c|}
\hline & PE & EE & SI & CT & PC & Acc & SUI \\
\hline PE & .750 & & & & & & \\
\hline EE & $.483^{* *}$ & .742 & & & & & \\
\hline SI & $.416^{* *}$ & $.544^{* *}$ & .716 & & & & \\
\hline CT & $.252^{* *}$ & $.511^{* *}$ & $.518^{* *}$ & .771 & & & \\
\hline PC & $-.128^{*}$ & -.099 & .015 & .015 & .876 & & \\
\hline ACC & $.489^{* *}$ & $.651^{* *}$ & $.631^{* *}$ & $.632^{* *}$ & -.082 & .752 & \\
\hline SUI & $.482^{* *}$ & $.602^{* *}$ & $.566^{* *}$ & $.492^{* *}$ & -.023 & $.639^{* *}$ & .677 \\
\hline
\end{tabular}

\subsection{Assessment of Structural Model and Hypotheses Testing}

Structural model analysis was undertaken to determine the relationships among the constructs in the proposed model, and subsequently determine the direction of significant paths between the constructs. The overall fit of the structural model was shown satisfactory, which was indicative of good model performance.

Table 4 shows that almost all the indexes of the structural equation basically reach the ideal value, which shows that the structural equation model is acceptable. The path parameters are shown in table IV which provide a basis for the following hypothesis verification.

Table 4: The path parameters

\begin{tabular}{|c|c|c|c|c|c|c|}
\hline \multicolumn{2}{|c|}{ Constructs Path } & S.E. & $\begin{array}{c}\text { C.R. } \\
\text { (T-value) }\end{array}$ & P & $\begin{array}{c}\text { Standardize } \\
\text { Estimate (Beta) }\end{array}$ \\
\hline Acc & $\leftarrow$ & PE & 0.044 & 2.289 & $0.022^{*}$ & 0.126 \\
\hline Acc & $\leftarrow$ & EE & 0.118 & 3.169 & $0.002^{* *}$ & 0.418 \\
\hline Acc & $\leftarrow$ & SI & 0.094 & 2.652 & $0.008^{* *}$ & 0.287 \\
\hline Acc & $\leftarrow$ & CT & 0.049 & 2.04 & $0.041^{*}$ & 0.113 \\
\hline Acc & $\leftarrow$ & PC & 0.024 & -1.185 & 0.236 & -0.042 \\
\hline SUI & $\leftarrow$ & Acc & 0.083 & 2.819 & $0.005^{* *}$ & 0.210 \\
\hline
\end{tabular}

The results for the structural path analysis indicate the model's structural paths. Four of the model's five paths are statistically significant at the 0.05 level of significance. After cross-matching the results of structural path analysis with the hypotheses, four hypotheses (H1, H2, H3, and H4) were supported and one (H5) were rejected. 
Of these five influencing factors, Effort Expectancy (EE) was the factor with the most influence, followed by SI, PE, and CT.

\section{Research Findings and Their Implications}

The results from the testing of the hypotheses derived from the research model reveals that Malaysian consumers' perceptions of cost has no statistically significant relationship with the acceptance of mobile payment. On the other hand, the factor of effort expectancy, social, the results show that the two constructs of UTAUT, Effort Expectancy (EE) and Performance Expectancy (PE), may influence consumers' acceptance of mobile payment. As to Effort Expectation (EE), if a mobile payment service provider provides a userfriendly payment process to use, consumers will feel like to accept mobile payment service. The conclusion of this study proves that although mobile payment has not been fully popularized in Malaysia, users have perceived the effort expectancy of this service, and it may have a significant impact on the behavioral intention of adopting the technology. Many researchers have observed the same results, this result is consistent with the findings of some researchers in mobile payment research (Oye, 2014; Martins et al., 2014; Ramon et al. 2019). As to Performance Expectancy (PE), the results show that there was a significant positive correlation between performance expectation and acceptance. This shows that the performance expectancy of mobile payment services as a convenient payment transaction has become an important factor in persuading Malaysian consumers to use such services. People in Malaysia recognize that mobile payment has many advantages over traditional payment methods such as cash and credit card. This conclusion is consistent with that of some previous researches (Martins et al., 2014; Ramon et al., 2019).

Social Influence has a significant impact on consumers' willingness to use mobile payment services. Previous scholars have come to similar conclusions (Oliveira, 2016; Mun, 2017; Andre, 2019). This factor is used to measure the influence of important peers and social groups on individual behavior. The influence of friends, parents and colleagues may become a key determinant in the decision-making process for potential users to adopt mobile payment services. In the early stages of mobile payment adoption, information about services among potential adopters will be limited. For people who have not previously used this service, they may rely heavily on other people's opinions to help them make decisions. While for consumers who have already adopted mobile payment, the importance of maintaining their social relations also encourages them to continue to adopt the service.

The impact of social influence as a significant factor affecting behavioral intention implies that if mobile payment service were adopted by relatives and friends, or leaders and colleagues, it will be more likely for consumers to adopt. This finding might be attributed to the culture in Malaysia society. As we all know, Malaysia is famous for its multi-ethnic culture where People attach importance to interpersonal relationships, care for others, protect the environment and equality, and are interpersonal oriented in the 
process of communication. Due to this characteristic, it could be assumed and tested social influence plays an important role in acceptance of mobile payment.

According to data analysis, Consumer Trust is proved to be a factor affecting people's attitude to mobile payment services, and many researches supported that Consumer Trust is positively related to consumers' electronic commerce behavior including mobile payment and mobile banking (Qiu et al, 2008; Chong et al., 2012; Phonthanukitithaworn, 2016; Tham, 2018). This finding suggests that consumers will not use mobile payment if they feel that they lack trust in entities associated with the provision of mobile payment services. This lack of trust may be a fundamental problem for consumers to refuse to provide personal information to mobile payment providers. It is important to build trust among potential users of mobile payment services because individuals who have no experience with mobile payment may be insecure in wireless transactions that are invisible to them.

This study believes that consumer trust is considered to be related to Malaysians' avoidance of uncertainty in financial practice. People attach importance to safe and clear rules. Because people highly avoid uncertainty, they are very concerned about safety and procedural norms. In particular, in the process of mobile payment transactions, money, products and recipients are not present. They may also worry about whether the mobile payment platform provides a secure transaction system to protect their personal information, such as credit card details and passwords, from fraud or criminal use. In this case, consumer trust is indeed a factor that has an important impact on the acceptance of mobile payment.

The results of this study show that there is no statistical correlation between Perceived Cost (PC) and consumer' acceptance of mobile payment, which may be inconsistent with the research conclusions of some scholars (Wei et al., 2009; Phonthanukitithaworn, 2016). The reason may be that the current mobile payment cost in Malaysia is relatively low. Users only need to use a small amount of mobile data to complete the operation of the mobile payment platform. In addition, to complete the transfer from the mobile payment platform to the bank, only a very low commission charge is required. In short, the total cost of mobile payment is relatively low. Most people think these costs are reasonable.

This study uses a combination of theoretical research and empirical analysis. Based on the investigation of the current situation of mobile payment among Malaysians, this paper formulates hypotheses, establishes a model, analyzes the factors affecting Malaysians' use of mobile payment, and enriches the research on Malaysian users' acceptance of mobile payment.

The results of this study also have important practical significance for the spread and management of mobile payment industry in Malaysia. Firstly, mobile payment platform should optimize process operations to improve consumers' perceived ease. From the empirical analysis of this study, it is known that perceived ease of use will positively affect consumer acceptance of mobile payments. Mobile payment software should be designed with a simpler interface, designed to be a smoother payment process, 
provide consumers with a better user experience, and make users think that mobile payment is easier to use. Secondly, mobile payment platform should improve consumers' feeling of usefulness. The convenience of mobile payments is extremely attractive to consumers, which is the biggest competitive advantage of mobile payments compared to other traditional payment instruments. To further promote mobile payment, mobile payment operators need to continuously enhance customers' feelings and provide consumers with better services. Consumers' usage habits can be gradually cultivated if the performance expectancy is improved. Thirdly, mobile payment platform should reduce user perceived risk and enhance user trust. This study shows that people always concern about their security issues before they accept mobile payment. Mobile payment operators need to emphasize security in the measurement of security and thus enhance consumer trust. Mobile payment industry standards should be specified in order to enhance the security and stability of mobile payment. The terminal, client and technology platform should fully guarantee the security of input, processing, and storage in the users' payment process, thus mobile payment can achieve the highest level of financial security through the testing and certification of the designated organization. Lastly, mobile payment platform should pay attention to social influence. As this study shows, social influence has a significant impact on the acceptance of mobile payment. Social relations and good reputation play important roles in the spread of mobile payments. Individuals or groups around the customer may influence on customers' use of mobile payments. Therefore, mobile payment operators should attach the importance to social influence, and at the same time, create a social atmosphere for mobile payment through multiple channels through online and offline activities. It is necessary to strengthen the depth and breadth of publicity, enrich the form of the ad to establish a good brand image. In addition, it is important to ensure that consumers receive various kinds of consultations on mobile payment services anytime, anywhere, and conveniently so that users can ubiquitously feel the mobile payment. Thus, consumers' habit of using mobile payment can be cultivated, and it is possible to integrate it into the users' daily life.

\section{Conclusion}

This paper reports a study on the acceptance of mobile payment and its sustainable usage intention in Malaysia. This paper proposes a theoretical model that includes the relevant psychological measurement factors that affect consumers' acceptance of mobile payment, and conducts an empirical test to verify it. It is found that effort expectancy, performance expectancy, subjective influence and consumer trust affect Malaysian consumers' acceptance of mobile payment.

The results of this study have some implications for the mobile payment service agents in Malaysia, as it helps them to understand the consumer behavior in the decisionmaking process of adopting mobile payment, and points out the areas they can focus on to encourage people to adopt and use the service. 


\section{Limitations and Directions for Future Study}

This study inevitably confronts limitations. This paper assumes five independent variables, namely effort expectancy, performance expectancy, social influence, consumer trust, perceived cost, and other factors that are not discussed in detail in this paper. Therefore, in the follow-up study, scholars are advised to explore more factors affecting mobile payment acceptance. This study did not set any moderating variables, nor did it consider the moderating effects of demographic variables, for example, gender, age, and income. These situations may lead to the incompleteness of the research model, and the conclusions drawn may be one-sided. These are issues that need to be solved and improved by subsequent research.

\section{Conflict of Interest Statement}

The authors declare no conflicts of interests.

\section{About the Authors}

Cao Yong, PhD candidate at Management and Science University, Malaysia, supervised by Dr. Jacquline Tham, Professor Dr. Ali Khatibi and Dr. S. M. Ferdous Azam, distinguished academics and researchers at the same University.

Jacquline Tham (PhD), Senior lecturer in Postgraduate Centre, MSU, who majors in banking, business and management.

Professor Dr. Ali Khatibi (PhD), professor in Faculty of Business Management and Professional Studies, MSU, who majors in Marketing.

S. M. Ferdous Azam (PhD), Senior lecturer in Postgraduate Centre, MSU, who majors in finance, business and banking.

Professor Dr. Ali Khatibi and Dr. S. M. Ferdous Azam are outstanding academics with many publications, including books, textbooks, book chapters, journals, conference. Furthermore, they have substantial industry experience gamed from working for multinational corporations. Their successful supervision, research examination and academic awards have made them well-known in their research fields.

\section{References}

Amberg, M. (2004). Compass Acceptance Model for the analysis and evaluation of mobile service. International Journal of Mobile Communications, Volume 2 Issue 3, September 2004, pp.248-259.

Andre G. V., Baptista P. T. \& Setiowati R. (2019). The Determinants Factors of Mobile Payment Adoption in DKI Jakarta. Journal of Research in Marketing, [S.l.], v. 10, n. 3, p. 823-831, Aug. 2019. ISSN 2292-9355. 
Bass F. M. (1969). A new product growth model for consumer durables. Management Science. A New Product Growth for Model Consumer Durables, Management Science, vol. 15, No. 5, Theory Series (Jan., 1969), pp. 215-227.

Benazić, D. \& Tanković, A. C. (2015). Impact of Perceived Risk and Perceived Cost on Trust in the Online Shopping Websites and Customer Repurchase Intention, 24th CROMAR congress: Marketing Theory and Practice - Building Bridges and Fostering Collaboration, Volume: ISBN: 978-953-281-067-7, Oct, 2015.

Bryne, B. M. (2010). Structural Equation Modeling with Amos: Basic Concepts, Applications and Programming, Routledge, New York.

Chandra, S., Srivastava, S. C., \& Theng, Y.-L. (2010). Evaluating the Role of Trust in Consumer Adoption of Mobile Payment Systems: An Empirical Analysis. Communications of the Association for Information Systems, 27.

Cheong, J. H. \& Park M. (2005). Mobile internet acceptance in Korea, Internet Research, Vol. 15 No. 2, pp. 125-140.

Chong, A. Y.-L., Chan F. T. \& Ooi K.-B. (2012). Predicting consumer decisions to adopt mobile commerce: cross country empirical examination between China and Malaysia. Decision Support Systems, Vol. 53 No. 1, pp. 34-43.

Cocosila, M., \& Trabelsi, H. (2016). An integrated value-risk investigation of contactless mobile payments adoption. Electronic Commerce Research \& Applications, 20, 159-170.

Garbarino, E. \& Johnson, M. (1999). The different roles of satisfaction, trust and commitment for relational and transactional consumers. Journal of Marketing, 63(2), 70-87.

Ghazali, E. M. (2018). Do consumers want mobile commerce? A closer look at Mshopping and technology adoption in Malaysia, Asia Pacific Journal of Marketing and Logistics, Vol. 30 Issue:4, pp.1064-1086.

Kim, G., Shin, B. \& Lee, H. G. (2009). Understanding Dynamics between Initial Trust and Usage Intentions of Mobile Banking. Information Systems Journal, 19, 3, 283-311.

Martins C., Oliveira, T., \& Popovic, A. (2014), Understanding the Internet banking adoption: A unedified theory of acceptance and use of technology and perceived risk application. International Journal of Information Management.

Mun, Y. P., Khalidb, H. \& Nadarajaha, D. (2017). Millennials' Perception on Mobile Payment Services in Malaysia, Procedia Computer Science, Volume 124, 2017, Pages 397-404.

Musa A., Khan, H. and AlShare, K. (2015). Factors influence consumers' adoption of mobile payment devices in Qatar. International Journal of Mobile Communications, 13(6), 670-689.

Oliveira T., Thomas M., Baptista G. \& Campos F. (2016). Mobile payment: Understanding the determinants of customer adoption and intention to recommend the technology. Computers in Human Behavior, 61, 404-414.

Ooi Widjaja, E. P. (2016). Non-Cash Payment Options in Malaysia, Journal of Southeast Asian Economies, 33(3), p. 398. 
Oye N. D., Iahad N. A., \& Rahim N. A. (2014). The history of UTAUT model and its impact on ICT acceptance and usage by academicians. Education and Information Technologies, 19, 251-270.

Phonthanukitithaworn, C., Sellitto, C. \& Fong, M. W. L. (2016). An investigation of mobile payment (m-payment) services in Thailand, Asia-Pacific Journal of Business Administration, Vol. 8 Issue: 1, pp.37-54.

Qasim, H. \& Abu-Shanab, E. (2016). Drivers of mobile payment acceptance: The impact of network externalities, Information Systems Frontiers, October 2016, Volume 18, Issue 5 pp. 1021-1034.

Qiu, L. Y. \& Li, D. (2008). Applying TAM in B2C e-commerce research: An extended model. Tsinghua Science and Technology, 13(3): 265-272.

Ramon P. S., Santiago F. C., Javier S. G. \& Emilio R. (2019). User Acceptance of Mobile Apps for Restaurants: An Expanded and Extended UTAUT-2. Sustainability 11(4), 1210.

Sekaran, U. \& Bougie, R. (2010). Research methods for business: A skill-building approach (5th ed.). Haddington: John Wiley \& Sons.

Slade E., Dwivdei Y., Piercy N. and Williams M. (2015). Modeling Consumers' Adoption Intentions of Remote Mobile Payments in the United Kingdom: Extending UTAUT with Innovativeness, Risk, and Trust. Psychology \& Marketing vol. 32(8), 860-873.

Soane, E., Dewberry, C. \& Narendran, S. (2010). The role of perceived costs and perceived benefits in the relationship between personality and risk-related choices, Journal of Risk Research, 13:3, pp. 303-318.

Tham, J. (2018). Achieving customer satisfaction through virtual banking perception in Malaysia. Doctoral thesis, Management and Science University, Malaysia.

Ting, H., Yacob, Y., Liew, L. \& Lau, W. M. (2016). Intention to use mobile payment system: A Case of Developing Market by Ethnicity. Procedia - Social and Behavioral Sciences, 224, 368-375.

Venkatesh, V., Morris, M. G., Davis, G. B. \& Davis, F. D. (2003). User acceptance of information technology: Toward a unified view. MIS Quarterly: Management Information Systems, 27(3), 425-478.

Wei, T. T., Marthandan, G., Chong, A. Y. L., Ooi, K. B. \& Arumugam, S. (2009). What drives Malaysian m-commerce adoption? An empirical analysis, Industrial Management \& Data Systems, Vol. 109 No. 3, pp. 370-388.

Zhang, L., Zhu, J. \& Liu, Q. (2012). A Meta-Analysis of Mobile Commerce Adoption and the Moderating Effect of Culture. Computers in Human Behavior, 28, 5, 1902-1911. 

that the materials are being reused under permission of a Creative Commons License. Views, opinions and conclusions expressed in this research article are views, opinions and conclusions of the author(s). Open Access Publishing Group and European Journal of Economic and Financial Research shall not be responsible or answerable for any loss, damage or liability caused in relation to/arising out of conflict of interests, copyright violations and inappropriate or inaccurate use of any kind content related or integrated on the research work. All the published works are meeting the Open Access Publishing requirements and can be freely accessed, shared, modified, distributed and used in educational, commercial and non-commercial purposes under a Creative Commons Attribution 4.0 International License (CC BY 4.0). 